\title{
Electron Paramagnetic Resonance Spin Trapping of Sunflower and Olive Oils Subjected to Thermal Treatment: Optimization of Experimental and Fitting Parameters
}

Angela Fadda ${ }^{a, *}$, Maria Giovanna Molinua ${ }^{a}$ Pierfrancesco Deianac ${ }^{c}$ Daniele Sanna ${ }^{b, *}$

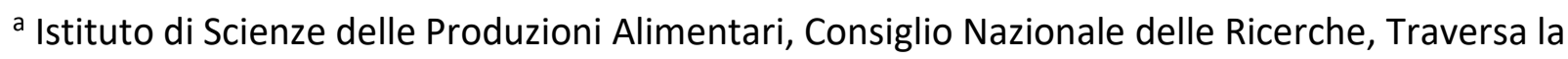
Crucca 3, Sassari, Italy

b Istituto di Chimica Biomolecolare, Consiglio Nazionale delle Ricerche, Traversa La Crucca 3, Sassari, Italy

c Dipartimento di Agraria, Università degli Studi di Sassari, viale Italia 39, Sassari, Italy.

* corresponding authors: Angela Fadda, angela.fadda@cnr.it; Daniele Sanna, daniele.sanna@cnr.it;

\section{SUPPLEMENTARY INFORMATION FOR PUBLICATION}

- Table S1. Concentration of the main phenolic compounds in olive oil determined by HPLC.

- Table S2. Fitting parameters and goodness of fit calculated in Sunflower and Olive oils with the modified Boltzmann Sigmoidal and the Boltzmann reverse equations.

- Figure S1. PBN adduct.

- Figure S2. Experimental (full line) and simulated (dotted line) EPR spectrum of sunflower oil containing PBN obtained during thermal treatment at $90{ }^{\circ} \mathrm{C}$ after $1 \mathrm{~min}$.

- Figure S3. EPR spectral intensities (AU) of PBN-adducts of sunflower oil over time.

- Figure S4. Boltzmann sigmoid (solid line) and Boltzmann sigmoid modified (dotted line) equations. The Black point is the lag time calculated with the Boltzmann equation and the circle is the lag time calculated with the Boltzmann modified equation.

- Figure S5. Kinetic curves of sunflower $(\bullet)$ and olive oil (o) heated at $90^{\circ} \mathrm{C}$ with PBN $(125 \mathrm{mM}$ final concentration) in flat cell.

- Figure S6. Peroxide values and PBN adduct intensity of sunflower oil heated for $15 \mathrm{~h}$ at $90{ }^{\circ} \mathrm{C}$ in full volume ( $A$ and $B$ ) and reduced volume ( $C$ and $D)$ safe-lock sample tubes. Clear grey bars indicate $0.5 \mathrm{~mL}$ tubes, while black bars indicate $1.5 \mathrm{~mL}$ tubes.

- Figure S7. Peroxide value measured in sunflower oil heated at $90^{\circ} \mathrm{C}$ for 5 hours $(300 \mathrm{~min})$. Oil was mixed with PBN to get a final concentration of $62.5,125,250 \mathrm{mM}$. 

Table S1. Concentration of the main phenolic compounds in olive oil determined by HPLC.

\begin{tabular}{|c|c|}
\hline Phenolic compounds & $\begin{array}{c}\text { Concentration } \\
\left(\mathbf{m g ~ K g}^{-1}\right)^{\mathbf{x}}\end{array}$ \\
\hline Hydroxytyrosol & $5.35 \pm 0.05$ \\
\hline Tyrosol & $10.30 \pm 0.02$ \\
\hline Oleacein & $74.52 \pm 0.58$ \\
\hline Oleocanthal & $111.96 \pm 2.40$ \\
\hline Oleuropein aglycone & $65.57 \pm 4.86$ \\
\hline Ligstroside aglycone & $54.74 \pm 2.60$ \\
\hline Vanillic acid & $0.89 \pm 0.00$ \\
\hline Vanillin & $0.84 \pm 0.00$ \\
\hline$p$-coumaric acid & $0.45 \pm 0.00$ \\
\hline$o$-coumaric acid & $0.04 \pm 0.00$ \\
\hline Acetoxypinoresinol & $3.88 \pm 0.30$ \\
\hline Luteolin & $2.99 \pm 0.03$ \\
\hline Apigenin & $2.07 \pm 0.00$ \\
\hline Total & $333.60 \pm 10.64$ \\
\hline
\end{tabular}


Table S2. Fitting parameters and goodness of fit calculated in Sunflower and Olive oils with the modified Boltzmann Sigmoidal and the Boltzmann reverse equations.

\begin{tabular}{|c|c|c|c|c|c|c|}
\hline $\begin{array}{l}\text { Curve fitting } \\
\text { parameters }\end{array}$ & Sunflower oi & & & Olive oil & & \\
\hline \multicolumn{7}{|c|}{$\begin{array}{l}\text { Modified Boltzmann Sigmoidal equation } \\
\text { Best fit values }\end{array}$} \\
\hline Bottom & -20485 & -23630 & -3725 & -13119 & -8464 & -6407 \\
\hline Top & 526814 & 574676 & 261881 & 494365 & 388759 & 406483 \\
\hline V50 & 76,55 & 87,96 & 81,25 & 101,3 & 117,4 & 116,9 \\
\hline Slope & 18,72 & 22,39 & 20,63 & 31,23 & 28,9 & 25,91 \\
\hline $\begin{array}{l}\text { Rise } \\
\text { Goodness of }\end{array}$ & 2490 & 2072 & 1400 & 133,1 & 634,8 & 818,9 \\
\hline $\mathrm{R}$ squared & 0,9996 & 0,9994 & 0,9987 & 0,9986 & 0,9995 & 0,9995 \\
\hline \multicolumn{7}{|c|}{$\begin{array}{l}\text { Boltzmann reverse equation } \\
\text { Best fit values }\end{array}$} \\
\hline Top & 811285 & 973023 & 512203 & 585325 & 514294 & 604769 \\
\hline Final & 422721 & 625323 & 256682 & 524788 & 375213 & 478277 \\
\hline $\mathrm{Mid}_{2}$ & 146,7 & 156,8 & 160,3 & 201,9 & 223,3 & 215,3 \\
\hline Slope & 9,846 & 4,894 & 4,848 & 6,482 & 9,051 & 7,136 \\
\hline $\begin{array}{l}\text { Decline } \\
\text { Goodness of }\end{array}$ & 201,8 & 1142 & 597,6 & 598,8 & 230,2 & 476,7 \\
\hline $\mathrm{R}$ squared & 0.9998 & 0,9987 & 0,9997 & 0,9942 & 0.9992 & 0.9992 \\
\hline
\end{tabular}




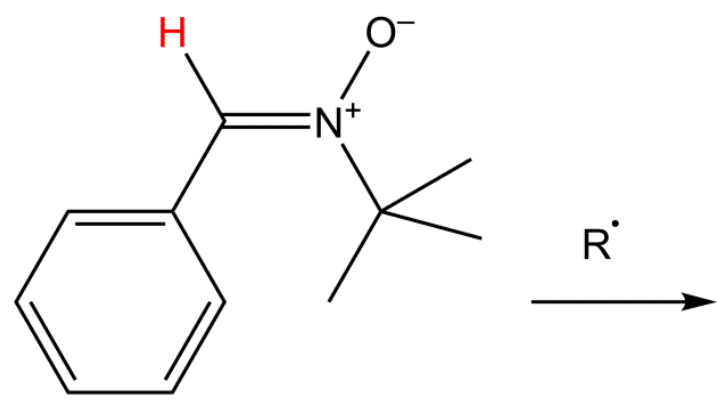

PBN

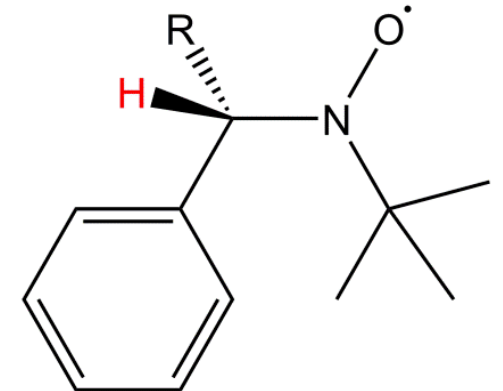

PBN adduct

Figure S1. PBN and its radical adduct showing, in red, the $\beta$ hydrogen mentioned in the text manuscript. 


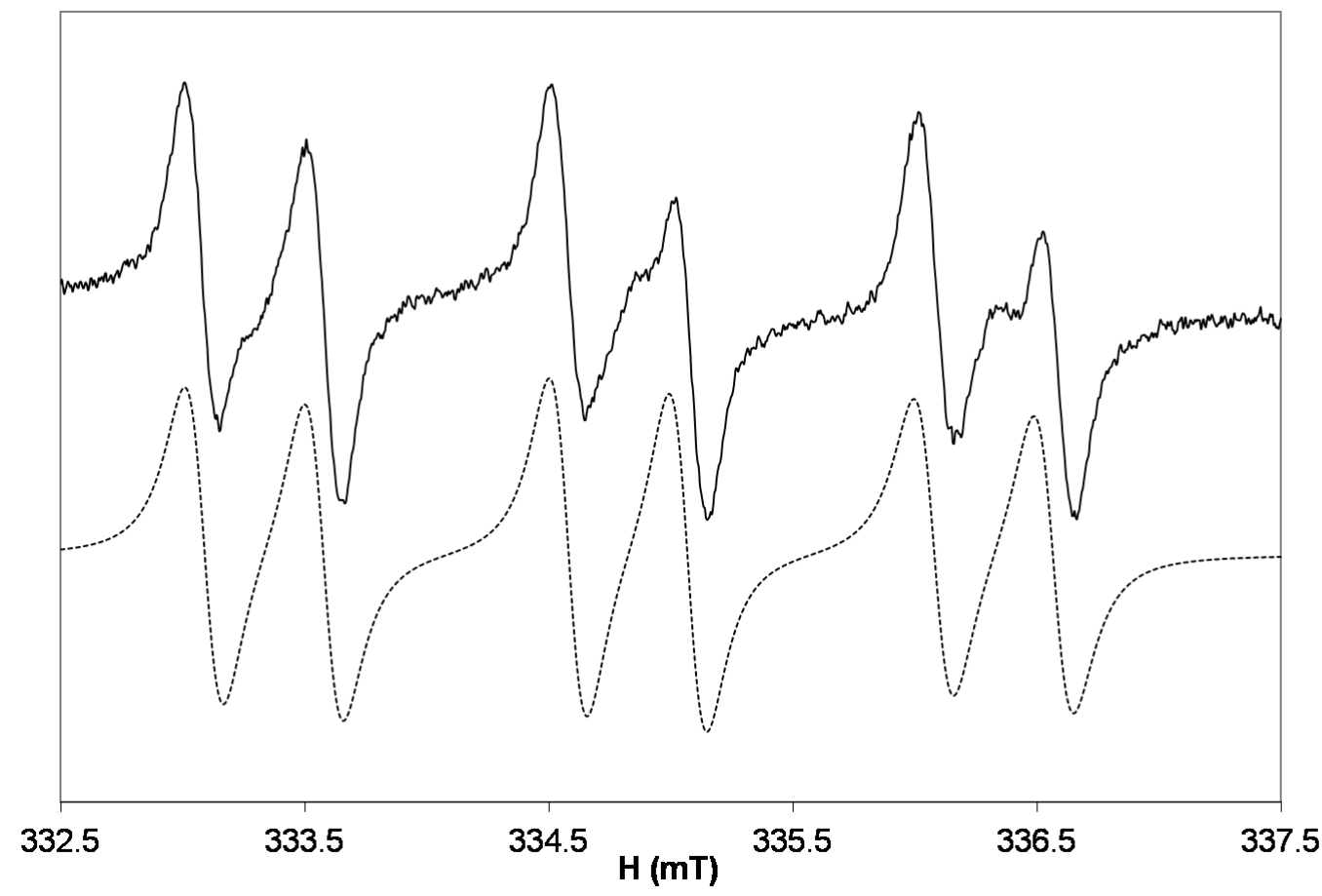

Figure S2. Experimental (full line) and simulated (dotted line) EPR spectrum of sunflower oil containing PBN obtained during thermal treatment at $90{ }^{\circ} \mathrm{C}$ after $1 \mathrm{~min}$. 


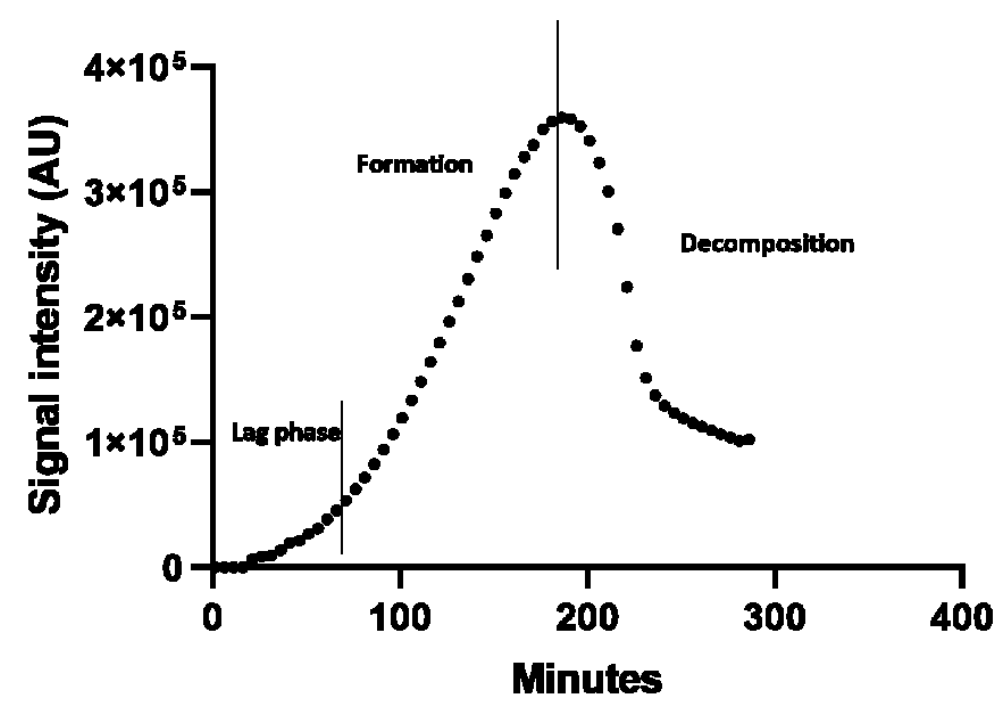

Figure S3. EPR spectral intensities (AU) of PBN-adduct of sunflower oil over time. 


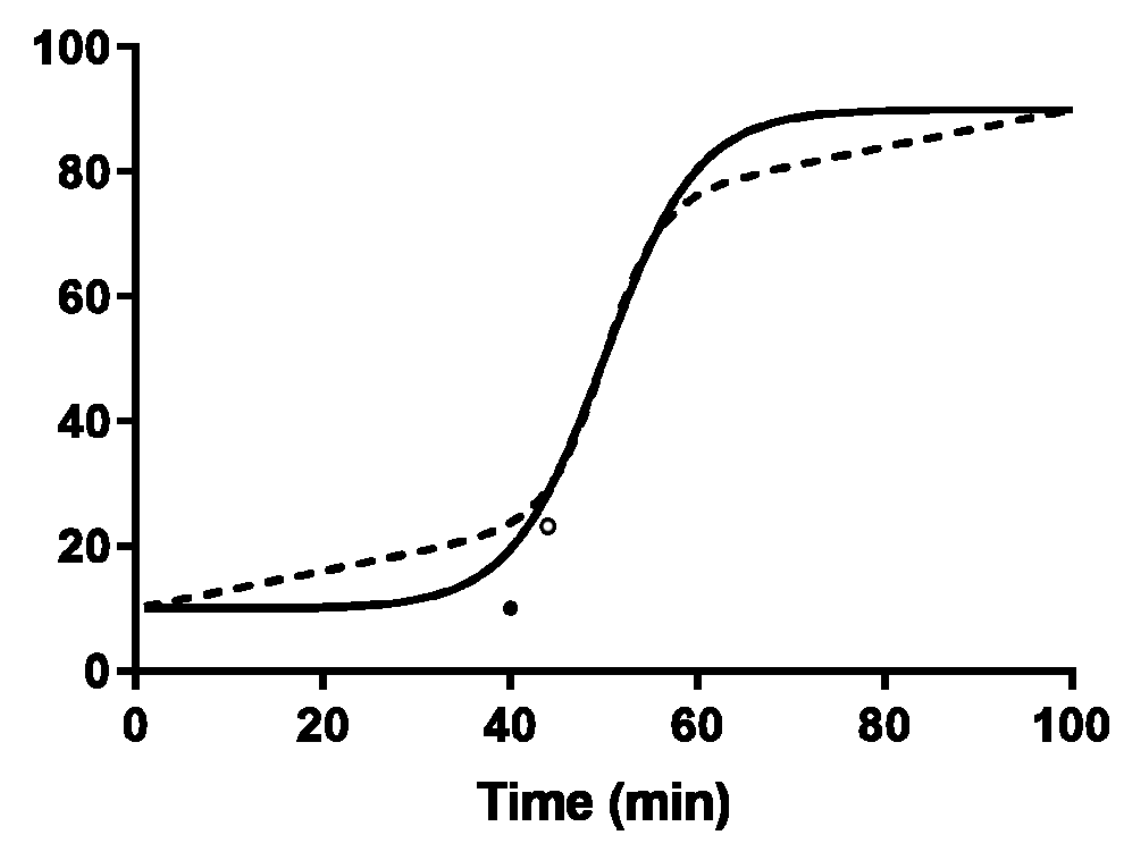

Figure S4. Boltzmann sigmoid (solid line) and Boltzmann sigmoid modified (dotted line) equations. The Black point is the lag time calculated with the Boltzmann equation and the circle is the lag time calculated with the Boltzmann modified equation. 


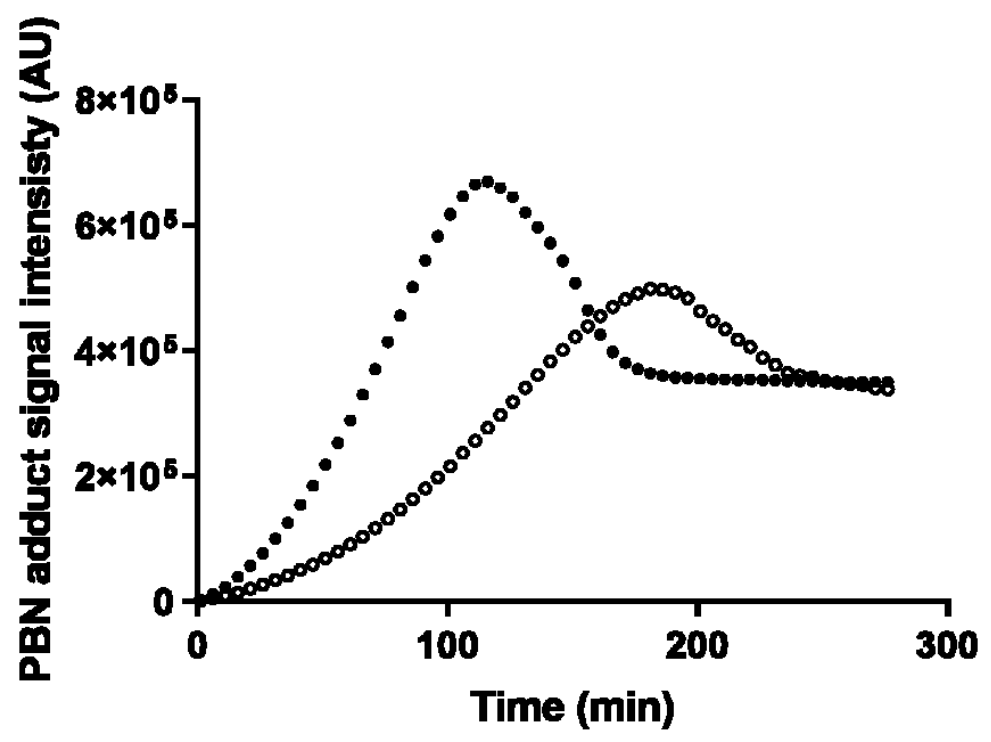

Figure S5. Kinetic curves of sunflower $(\bullet)$ and olive oil (o) heated at $90{ }^{\circ} \mathrm{C}$ with PBN $(125 \mathrm{mM}$ final concentration) in flat cell. 

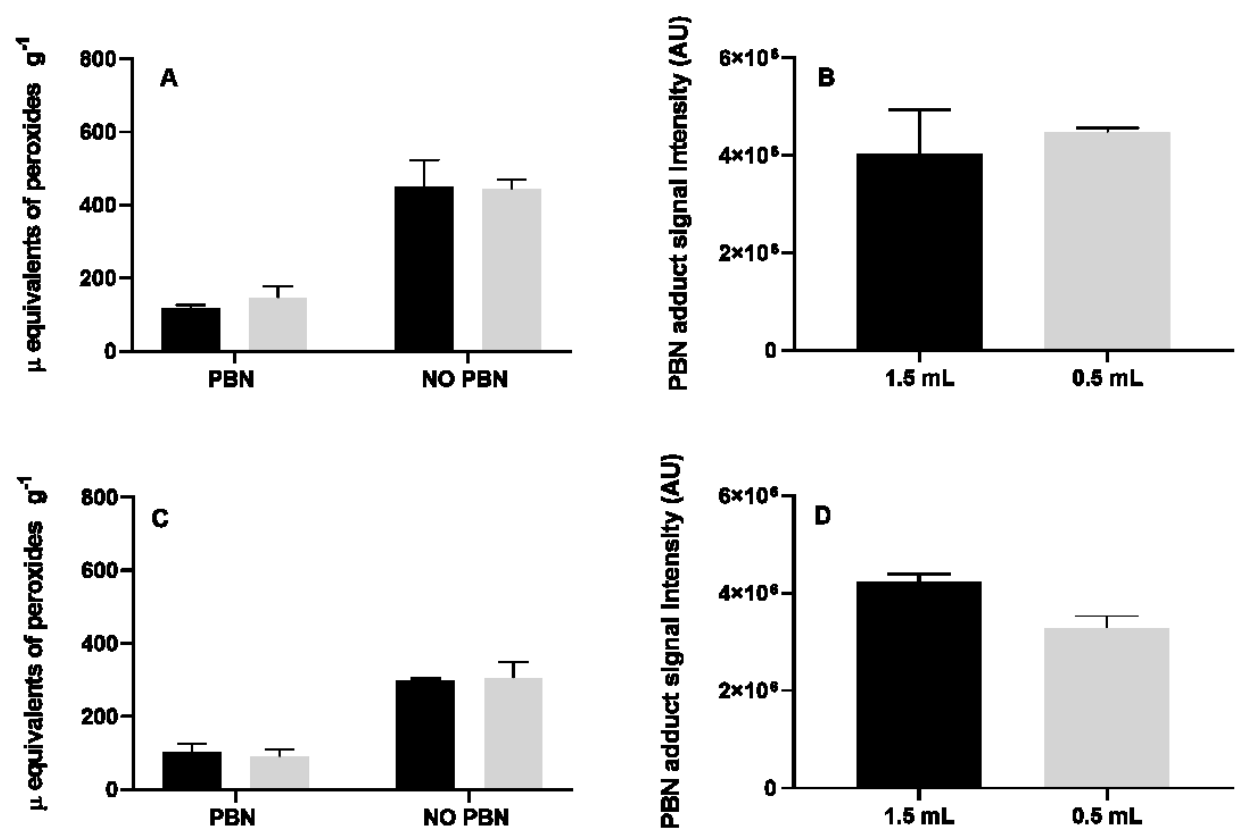

Figure S6. Peroxide values and PBN adduct intensity of sunflower oil heated for $15 \mathrm{~h}$ at $90{ }^{\circ} \mathrm{C}$ in full volume $(A$ and $B)$ and reduced volume $(C$ and $D)$ safe-lock sample tubes. Clear grey bars indicate 0.5 $\mathrm{mL}$ tubes, while black bars indicate $1.5 \mathrm{~mL}$ tubes. 


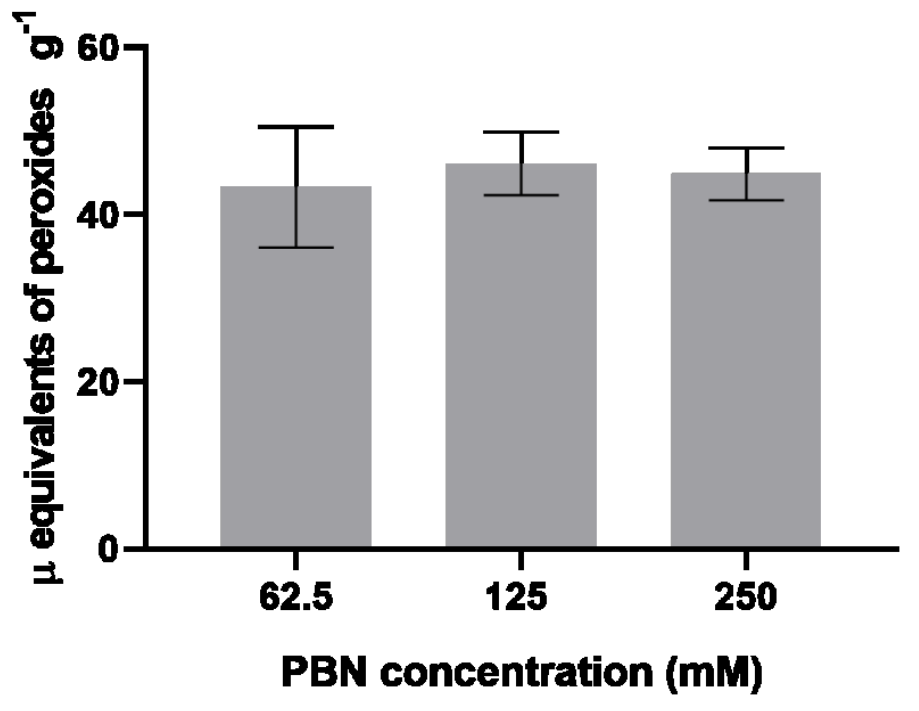

Figure S7. Peroxide value measured in sunflower oil heated at $90^{\circ} \mathrm{C}$ for 5 hours ( $300 \mathrm{~min}$ ). Oil was mixed with PBN to get a final concentration of $62.5,125,250 \mathrm{mM}$. 